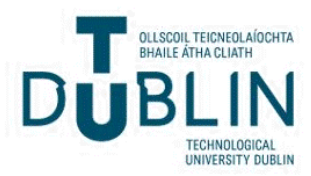

Technological University Dublin

ARROW@TU Dublin

2010-04-01

\section{Reconfigurable Antenna with Elevation and Azimuth Beam Switching}

\author{
S. Shynu \\ Technological University Dublin, sshynu@tudublin.ie \\ Max Ammann \\ Technological University Dublin, max.ammann@tudublin.ie
}

Follow this and additional works at: https://arrow.tudublin.ie/ahfrcart

Part of the Systems and Communications Commons

\section{Recommended Citation}

Nair,S., Ammann, M. (2010) Reconfigurable Antenna with Elevation and Azimuth Beam Switching. IEEE Antennas and Wireless Propagation Letters, Vol.9, 2010, pp367-370. doi:10.1109/LAWP.2010.2049332

This Article is brought to you for free and open access by the Antenna \& High Frequency Research Centre at ARROW@TU Dublin. It has been accepted for inclusion in Articles by an authorized administrator of ARROW@TU

Dublin. For more information, please contact

arrow.admin@tudublin.ie, aisling.coyne@tudublin.ie, gerard.connolly@tudublin.ie.

Funder: Science Foundation Ireland

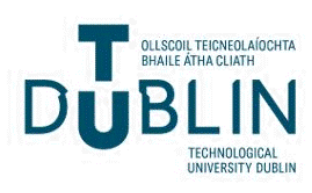




\title{
Reconfigurable Antenna With Elevation and Azimuth Beam Switching
}

\author{
S. V. Shynu Nair, Member, IEEE, and Max J. Ammann, Senior Member, IEEE
}

\begin{abstract}
A reconfigurable microstrip antenna is proposed for low-cost adaptive beam-switching applications. A small patch-slotring structure is used as the radiating element where an asymmetrical arrangement of p-i-n diodes is employed to switch the pattern in four directions. The antenna provides pattern switching of $65^{\circ}$ and $45^{\circ}$ in its fundamental mode for the elevation and azimuth planes, respectively. By maintaining the resonant frequency and beamwidth as relatively constant, beam switching is realized using a single feed point.
\end{abstract}

Index Terms-Beam steering, p-i-n diodes, reconfigurable antenna.

\section{INTRODUCTION}

$\mathbf{P}$ ATTERN switchable antenna arrays are used in the emerging personal and in-building communication systems. Electronically steerable antenna arrays are preferred because of low maintenance, fast orientation speed, low power requirements, and small physical size. Electronic beam switching can be used in mobile applications to enhance spectral efficiency as well as reduce the problems associated with multipath propagation. Switched parasitic smart antenna arrays can adjust their pattern so that their main beam always points toward the mobile receiver or transmitter [1], [2]. The phased array is the most common type of electronically steerable array. With multiple radiating elements and a sophisticated control algorithm, it can achieve virtually unconstrained control over azimuth and elevation scan angles at reasonably high speeds. Conversely, many applications do not require such complexity, and thus an alternative, simpler system is desirable [3]-[5]. Other wireless technologies such as vehicle-to-vehicle communications have attracted attention due to their potential to prevent traffic accidents by gathering information from other vehicles. In vehicle-to-vehicle communications, pattern control improves the system performance [6]-[8]. Digital beamforming antennas have typical architectures for steering the beam, where $\mathrm{RF}$ chains are connected to individual radiating elements. A flat array antenna for beam switching using a $3-\mathrm{dB}$ coupler

Manuscript received March 05, 2010; accepted April 12, 2010. Date of publication April 29, 2010; date of current version May 10, 2010. This work was supported by Science Foundation Ireland under Grant 08/CE/I1523.

S. V. S. Nair is with the CTVR, The Telecommunications Research Centre, School of Electronic and Communications Engineering, Dublin Institute of Technology, Dublin 2, Ireland. (e-mail: shynunair@gmail.com).

M. J. Ammann is with the Antenna \& High Frequency Research Centre, School of Electronic and Communications Engineering, Dublin Institute of Technology, Dublin 8, Ireland (e-mail: max.ammann@dit.ie).

Color versions of one or more of the figures in this letter are available online at http://ieeexplore.ieee.org.

Digital Object Identifier 10.1109/LAWP.2010.2049332 and p-i-n diodes was recently developed for low-gain modern wireless communication systems. In this array, four-beams are switched in the H-plane by selecting the input port or p-i-n diode state [9]. A reactively steerable antenna that consists of one driven element and many parasitic elements terminated by variable reactance circuits provides a simpler architecture [10]. A reactively steerable antenna for cars has also been reported [11]. In the UHF band, single antenna elements will be required to have pattern control. A frequency-tunable dipole antenna with variable reactance circuits has been reported. This dipole with silicon photo switches was demonstrated to avoid unwanted radiation caused by leakage current on dc bias circuit. The dipole also provided elevation steering of $12^{\circ}$ for the direction of the maximum radiation [12]. However, single-element methods are limited by small steering angles and cannot switch the beam in two planes using a single feed operating at a fixed frequency.

In this letter, a novel single-feed microstrip antenna capable of beam switching in four different directions in the E- and $\mathrm{H}$-planes is proposed. A conical radiation pattern is realized in a patch-slot-ring combination, which can be shaped into a single lobe pattern, switchable in different directions. The conical pattern is produced by a constant current loop formed in the microstrip square-ring structure [13]-[15]. The fundamental $\mathrm{TM}_{11}$ mode of the microstrip ring is used rather than the higher order modes. The microstrip ring is excited using a small patch at its center and fed by a coaxial probe. Beam shaping is achieved by modifying the current distribution in the microstrip ring using a combination of shorts and shorting posts. For electronic beam switching, these shorts and shorting posts are replaced by $\mathrm{p}-\mathrm{i}-\mathrm{n}$ diode switches. This arrangement is less complex than an array, and the asymmetrical shorting of the slot-patch-ring structure can realize symmetrical beam switching in four different directions. Another advantage of this configuration is that it only has components on two sides of the ring and thus uses a smaller number of nonlinear components, reducing the cost and also the intermodulation generated due to the $\mathrm{p}-\mathrm{i}-\mathrm{n}$ diodes. The design procedure with integrated $\mathrm{p}-\mathrm{i}-\mathrm{n}$ diode switches and biasing circuitry is presented.

\section{ReCONFIGURABLe ANTENNA DESIGN}

The antenna consists of a small patch of dimension $8 \times 8 \mathrm{~mm}^{2}$ on an FR4 substrate of thickness $1.52 \mathrm{~mm}$ $\left(\epsilon_{\mathrm{r}}=4.3\right)$, fed using a coaxial probe, $2.5 \mathrm{~mm}$ offset from patch center. The patch is surrounded by a square microstrip ring of inner dimension $10 \mathrm{~mm}$ and outer dimension $15 \mathrm{~mm}$. The slot separation between the patch and the ring is $2 \mathrm{~mm}$. This patch-slot-ring structure is embedded in a metallic patch 


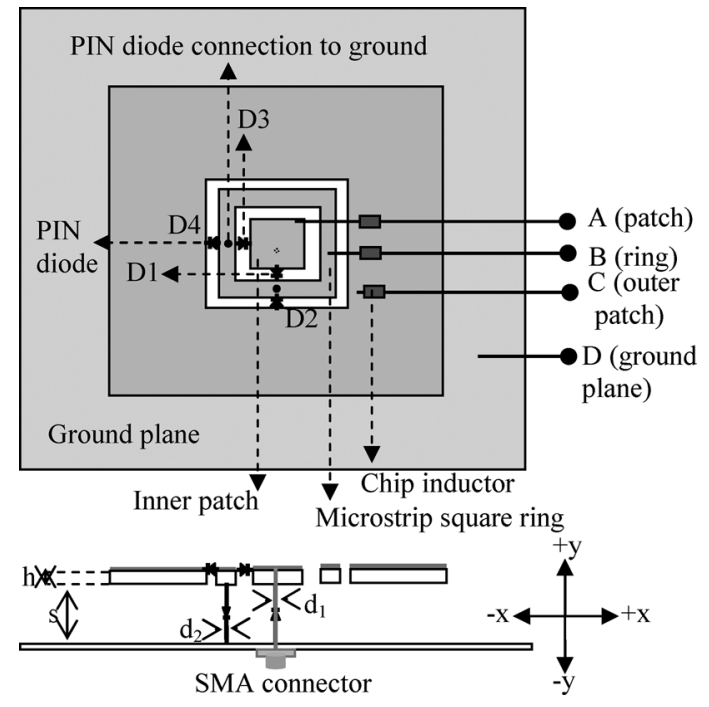

Fig. 1. The geometry of the proposed pattern reconfigurable antenna with integrated $\mathrm{p}$-i-n diode switches $\left(\mathrm{d}_{1}=1.35 \mathrm{~mm}, \mathrm{~d}_{2}=0.7 \mathrm{~mm}, \mathrm{~s}=6 \mathrm{~mm}\right.$, $\mathrm{h}=1.52 \mathrm{~mm}$ ).

of dimension $72 \times 68 \mathrm{~mm}^{2}$ as shown in Fig. 1. The structure is placed $6 \mathrm{~mm}$ above the ground plane of dimension $17.5 \times 17 \mathrm{~cm}^{2}$.

The current distribution in the ring can be changed either by shorting it to the central patch or to the outer patch. The conical beam is shaped to become more directive in the elevation and azimuth planes by modifying the current distribution in the ring using a combination of shorts and shorting posts. The shorts between the ring and the inner patch can provide a directive beam tilting toward the direction of the short. When the outer patch is connected to the ring using another short, the pattern switches toward the opposite direction. The ring itself is connected to the ground plane using a shorting post. To demonstrate the four operating modes and the corresponding beam switching capability, an equivalent passive model is shown in Fig. 2. The feed position in the inner patch is fixed for the four modes. This property significantly simplifies the conversion of the passive design to an electronically reconfigurable antenna with a switchable pattern. In general, complex multilayered capacitive feeding is necessary to obtain good matching of the high input impedance fundamental $\mathrm{TM}_{11}$ mode of the ring. In this case, the feed mechanism is simple with a small embedded patch at the center of the ring, which can maintain a 6-dB return loss even with different short positions.

For electronic beam switching, the shorts and shorting posts are replaced by $\mathrm{p}$-i-n diode switches. The four $\mathrm{p}$-i-n diodes integrated between the inner patch and the square rings are arranged so that only one diode is forward biased at a time. Hence, a single dc supply of $1.1 \mathrm{~V}$ is sufficient to bias the reconfigurable antenna. In general, to switch the beam in the elevation and azimuth planes, there must be a symmetrical placement of switches in the four respective directions of the radiating element. In the proposed design, $\mathrm{p}-\mathrm{i}-\mathrm{n}$ diode switches are only used in two directions $(-x$ and $-y)$ in order to switch the beam in four directions. The bias circuitry and battery are located behind the ground plane. The bias is applied across the outer and

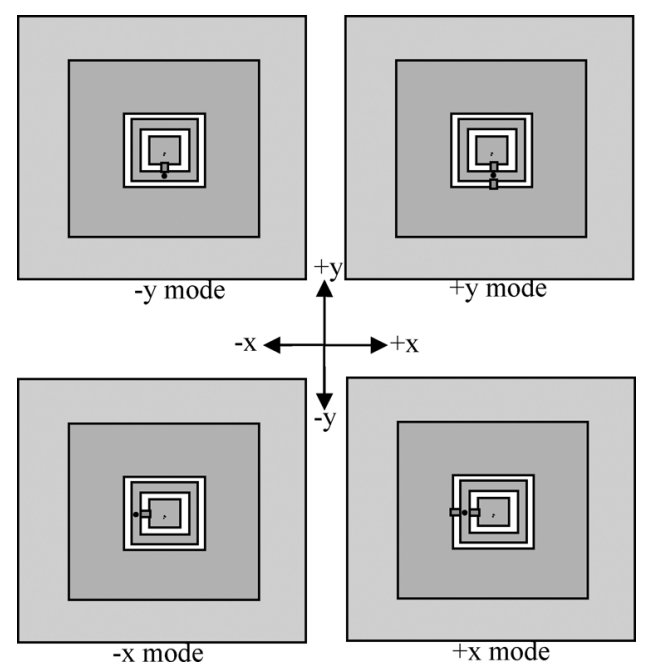

Fig. 2. Four equivalent passive antenna models with shorts and shorting posts.

TABLE I

BIASING AND BEAM DIRECTION FOR THE FOUR MODES

\begin{tabular}{ccccccc}
\hline \hline A & B & C & D & $\begin{array}{c}\text { Mode of } \\
\text { Operation }\end{array}$ & $\begin{array}{c}\text { Resonant } \\
\text { Frequency } \\
(\mathrm{GHz})\end{array}$ & $\begin{array}{c}\text { Beam } \\
\text { Direction }\end{array}$ \\
\hline+ & - & + & + & $+\mathrm{y}$ & 2.110 & $\theta=65^{\circ}$ \\
+ & - & open & + & $-\mathrm{y}$ & 2.087 & $\theta=130^{\circ}$ \\
- & + & - & - & $-\mathrm{x}$ & 2.051 & $\varphi=20^{\circ}$ \\
- & + & & & & & \\
\hline \hline
\end{tabular}

inner patches and to the square ring through three chip inductors to isolate the RF current. Biasing details for all the operating modes are illustrated in Table I.

\section{MeAsured Results}

Optimization of the antenna was carried out using CST Microwave Studio. $\mathrm{p}-\mathrm{i}-\mathrm{n}$ diodes in forward bias were modeled as $1-\Omega$ resistors and as $0.1-\mathrm{pF}$ capacitors in reverse bias. The measured and simulated $\mathrm{S}_{11}$ for the four modes are given in Figs. 3 and 4 , respectively. The 6-dB impedance bandwidth commonly available to all modes is $2.6 \%$ centered at $2.055 \mathrm{GHz}$. The simulated resonant frequencies for the four modes are slightly lower compared to the corresponding measured results mainly due to the parasitic effects of the six integrated $\mathrm{p}-\mathrm{i}-\mathrm{n}$ diodes and the bias chip inductors. Since the position of the feed is fixed and the position of the short and shorting post are changing (with different bias conditions), the relatively small shift in the resonant frequency is acceptable.

The pattern direction depends on the p-i-n diode biasing at the terminals A, B, C, and D in Fig. 1. When terminals A, C, and $\mathrm{D}$ are positive with respect to $\mathrm{B}$, the antenna operates in the $+y$ mode, switching the beam toward the $+y$-direction. When bias is removed from C, diode D2 is in an OFF state, and the beam turns toward the $-y$ direction ( $-y$ mode). Similarly, when A, C, and $\mathrm{D}$ are negative with respect to $\mathrm{B}$, the antenna operates in the 


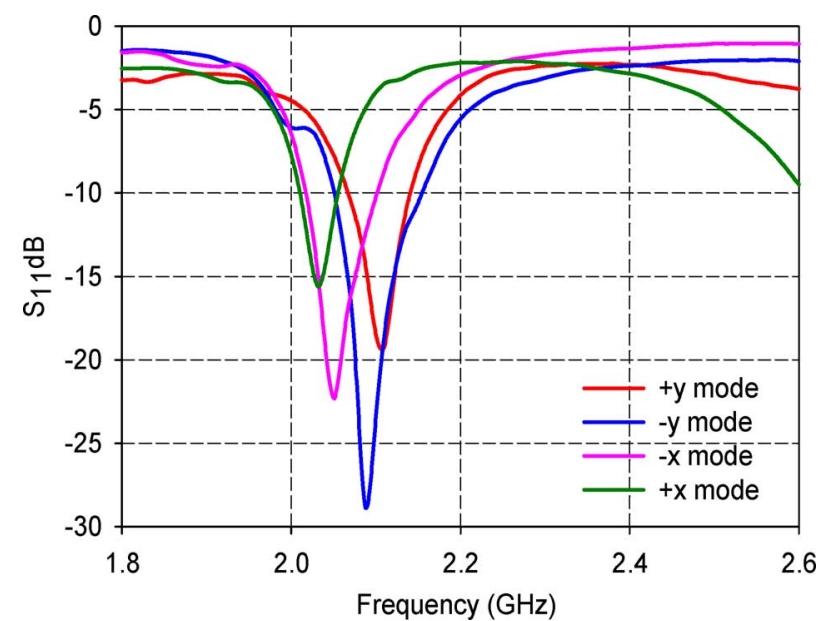

Fig. 3. Measured $\mathrm{S}_{11}$ for the four different operating modes.

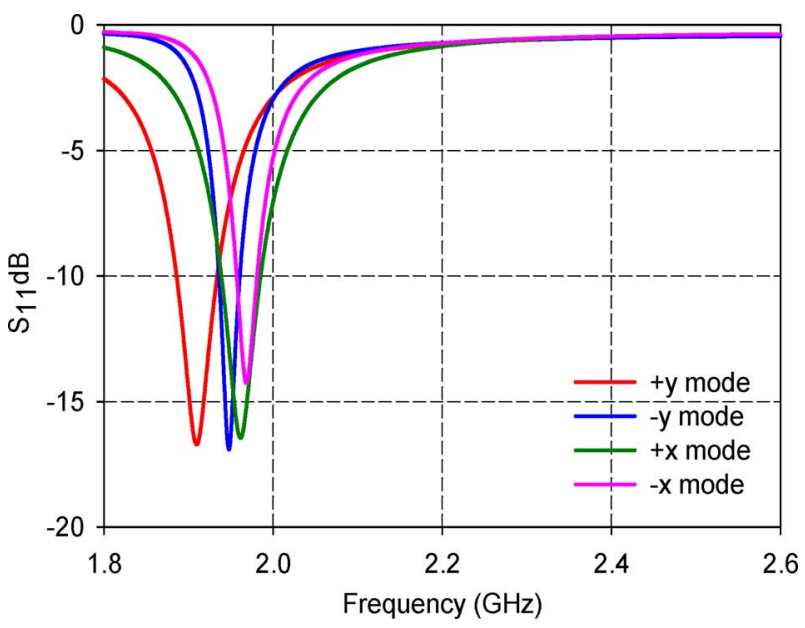

Fig. 4. Simulated $\mathrm{S}_{11}$ for the four different operating modes.

$-x$ mode, switching the beam toward the $-x$-direction. When bias is removed from C, diode $\mathrm{D} 4$ is OFF, and hence the beam turns toward the $+x$ direction ( $+x$ mode).

The measured 3-dB beamwidth is $55^{\circ}$ for both planes. The measured radiation patterns are shown in Fig. 5. The 3D simulated 3-dB patterns are shown in Fig. 6 for reference. The measured peak gain for the $-y,+y,-x,+x$ modes was $4.58,2.71$, 1.11 , and $3.2 \mathrm{dBi}$, respectively. The variation in gain for the modes is due to the asymmetry of the switching p-i-n diode arrangement. The lower gain for $-x$ mode is mainly attributed to the dc lines and biasing circuitry, which are directed along the $\mathrm{x}$-axis. These bias lines run from the radiating element and perturb the current distribution in the ring and patch structure for the $-x$ mode. Details of the beam direction and switching sequence are tabulated in Table I. The smaller scanning angle in the elevation plane compared to the azimuth plane is also attributed to the $-x$-directed bias lines. For single-element antennas, larger beam switching angles can only be achieved by using higher order leaky-wave modes or by complex multifeed arrangements. However, in this proposed design, switching angles of $65^{\circ}$ and $45^{\circ}$ are achieved using the $\mathrm{TM}_{11}$ fundamental mode of the microstrip ring. The gain is relatively high for an antenna with a large number of lumped elements integrated into
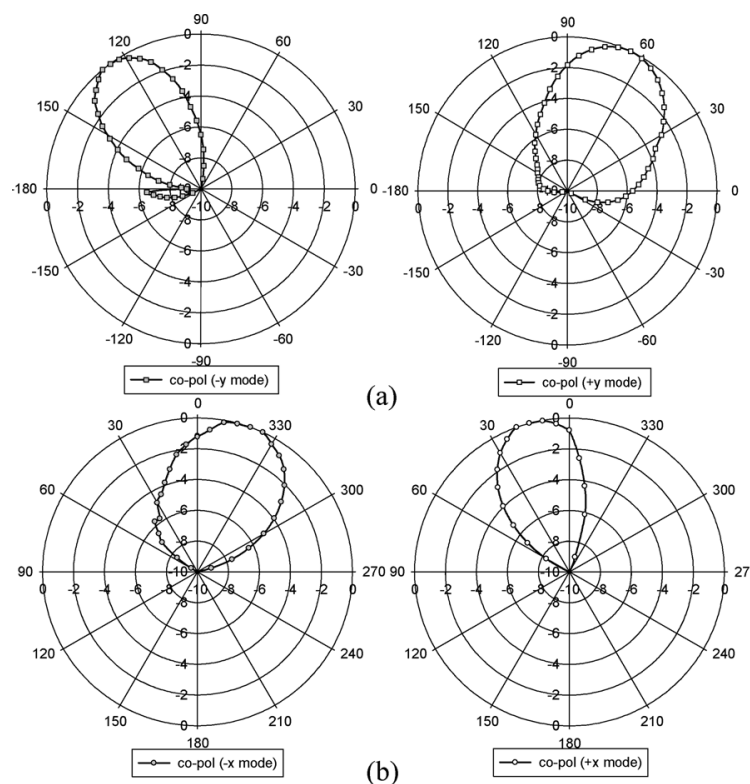

a)
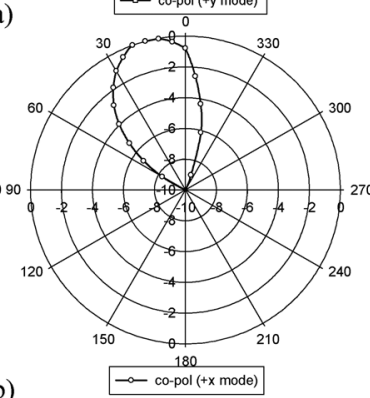

(b)

Fig. 5. Measured pattern for the four modes. (a) Azimuth plane ( $-y$ and $+y$ modes). (b) Elevation plane ( $-x$ and $+x$ modes). The cross-polar values are too small to be visible in the above scale.
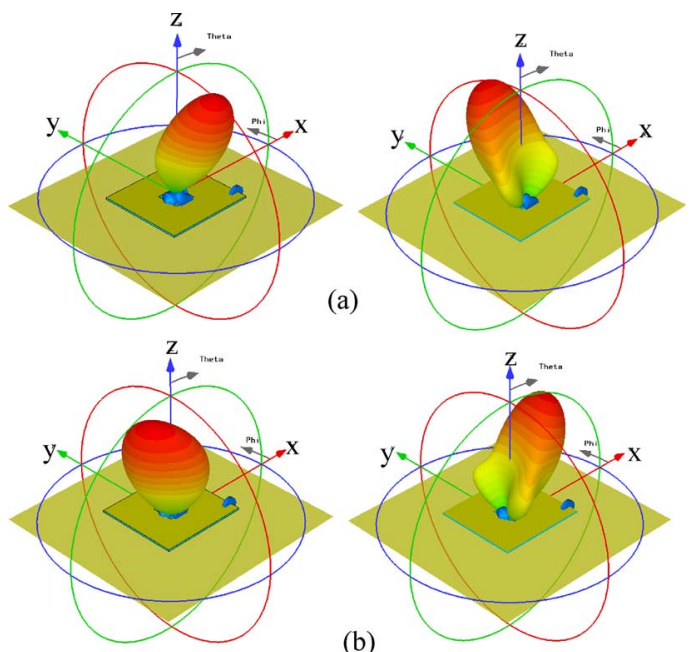

(b)

Fig. 6. Simulated 3D radiation pattern showing the beam direction in four operating modes. (a) Azimuth plane ( $-y$ and $+y$ modes). (b) Elevation plane ( $-x$ and $+x$ modes).

the radiating element. Thus, by keeping the resonant frequency and beamwidth relatively constant, this design can provide beam switching in the E- and H-planes with a single feed point.

\section{CONCLUSION}

A pattern reconfigurable microstrip antenna using integrated p-i-n diodes for beam switching in the elevation and azimuth planes is presented. The antenna has an asymmetrical switching scheme using a minimum number of lumped components, reducing the complexity, cost, and intermodulation characteristics. The antenna provides beam switching of $65^{\circ}$ and $45^{\circ}$ in the E- and H-planes, respectively. The proposed method is appropriate for adaptive beam switching in indoor wireless applications. 


\section{REFERENCES}

[1] A. T. Kolsrud, M. Y. Li, and K. Chang, "Dual-frequency electronically tunable CPW-fed CPS dipole antenna," Electron. Lett., vol. 34, no. 7, pp. 609-611, Feb. 1998.

[2] S. L. Preston, D. V. Thiel, J. W. Lu, S. G. O'Keefe, and T. S. Bird, "Electronic beam steering using switched parasitic patch elements," Electronic Lett., vol. 33, no. 1, pp. 7-8, Jan. 1997.

[3] C. Won, M. Lee, G. P. Li, and F. De Flaviis, "Reconfigurable beamscan single-arm spiral antenna with integrated MEMS switches," IEEE Trans. Antennas Propag., vol. 54, no. 2, pp. 455-463, Feb. 2006.

[4] Z. N. Chen, Antenna for Portable Devices. Hoboken, NJ: Wiley, 2007, ch. 3.

[5] C. C. Chang, C. Liang, B. H. Deng, C. W. Domier, and N. C. Luhmann Jr., "A beam-shaping phased antenna array based on true-time delay technologies," Infrared Millim. Waves, pp. 99-100, 2002.

[6] B. A. Cetiner, E. Akay, E. Sengul, and E. Ayanoglu, "A MIMO system with multifunctional reconfigurable antennas," IEEE Antennas Wireless Propag. Lett., vol. 5, pp. 463-466, 2006.

[7] G. Augustin, S. V. Shynu, C. K. Aanandan, P. Mohanan, and K. Vasudevan, "Reactive loaded slot line leaky-wave antenna for low cost beam steering applications," Microw. Opt. Technol. Lett., vol. 48, no. 11, pp. 2299-2301, Dec. 2006.
[8] D. V. Theil, S. O'Keefe, and J. E. Lu, "Electronic beam steering in wire and patch antenna systems using switched parasitic elements," in IEEE AP-S Int. Symp. Dig., 1996, pp. 534-537.

[9] H. Arai, "Beam switching flat antenna for modern communication systems," in Proc. EMTS, Ottawa, ON, Canada, Jul. 26-28, 2007, Paper 094.

[10] R. L. Li, V. F. Fusco, and R. Cahill, "Pattern shaping using a reactively loaded wire loop antenna," IEE Proc. Microw., Antennas Propag., vol. 148, pp. 03-208, Jun. 2008.

[11] H. Iizuka, T. Watanabe, K. Sato, and K. Nishikawa, "Modified $\mathrm{H}$-shaped antenna for automotive digital terrestrial reception," IEEE Trans. Antennas Propag., vol. 53, no. 8, pp. 2542-2548, Aug. 2005.

[12] C. J. Panagamuwa, A. Chauraya, and J. C. Vardaxoglou, "Frequency and beam reconfigurable antenna using photoconducting switches," IEEE Trans. Antennas Propag., vol. 54, no. 2, pp. 449-454, Feb. 2006.

[13] T. Minemura, T. Amano, and T. Morroka, "A study on loop antenna with uniform current distribution," in Proc. IEEE Antennas Propag. Soc. Int. Symp., Jun. 2004, vol. 3, pp. 3233-3236.

[14] Y. S. Wu and F. J. Rosenbaum, "Mode chart for microstrip ring resonators," IEEE Trans Microw. Theory Tech., vol. MTT-21, no. 7, pp. 487-489, Jul. 1973.

[15] C. C. Yu and K. Chang, "Transmission-line analysis of a capacitively coupled microstrip-ring resonator," IEEE Trans. Microw. Theory Tech., vol. 45, no. 11, pp. 2018-2024, Nov. 1997. 